\title{
Bel ağrılı hastalarda ağrı, kinezyofobi ve yaşam kalitesi arasındaki ilişki
}

The relationship between pain, kinesiophobia and quality of life in patients with low back pain

\author{
Sevtap Günay Uçurum \\ Aybuke Cansu Kalkan
}

İzmir Katip Çelebi Üniversitesi Sağlık Bilimleri Fakültesi, Fizyoterapi ve Rehabilitasyon Bölümü, İzmir, Türkiye

Öz

Amaç: Bel ağrısı klinikte en sık karşılaşılan ve yaşam kalitesini olumsuz etkileyen muskuloskeletal bir problemdir. Kinezyofobi varlığı bel ağrısı tedavisini olumsuz yöne etkileyebilir ve kişinin özür oranını arttırabilir. Çalışmamızda bel ağrısı olan kişilerde ağıı, yaşam kalitesi ve kinezyofobi arasındaki ilişkiyi karşılaştırmayı amaçladık.

Gereç ve Yöntem: Çalışmaya İzmir Kâtip Çelebi Üniversitesi Atatürk Eğitim ve Araştırma Hastanesi Fizik Tedavi ve Rehabilitasyon Kliniğine başvuran 80 bel ağrılı hasta (Yaş ortalamaları $45.29 \pm 14.97$ yıl) dâhil edildi. Ağrı "Görsel Anolog Skalası (GAS) ile, Kinezyofobi "Tampa Kinezyofobi Ölçeği (TKÖ)" ile ve SF-36 Yasam Kalitesi Anketi ile değerlendirilmiştir.

Bulgular: İstirahat GAS değeri ortalaması $3.10 \pm 2.75$, aktivite GAS değeri ortalaması $6.66 \pm 2.38$ olup ortalama kinezyofobi skoru $43.15 \pm 6.16$, ortalama SF-36 fiziksel komponent skoru $56.25 \pm 24.42$ ve ortalama SF-36 mental komponent skoru $62.95 \pm 20.56$ puandır. Bireylerin kinezyofobi değerleri ile yaşları $(r=0.237 / p=0.034)$, istirahat ve aktivite sırasındaki GAS değerleri $(r=0.242 / p=0.032-r=0.293 / p=0.008)$, eğitim durumları $(r=-0.279 / p=0.002)$, yaşam kalitesinin fiziksel $(r=-0.236 / p=0.035)$ ve mental komponenet $(r=-0.323 / p=0.003)$ parametreleri arasında anlamlı bir ilişki bulunmuştur.

Sonuç: Bel ağrılı hastalarda kinezyofobi yaş, istirahat ve aktivite ağrısıyla ile pozitif yönde zayıf bir ilişki gösterirken, eğitim durumu, yaşam kalitesinin fiziksel ve mental komponentleri ile negatif yönde zayıf bir ilişki göstermiştir.

Anahtar Sözcükler: Bel ağrısı, kinezyofobi, yaşam kalitesi.

\section{Abstract}

Aim: Low back pain is a musculoskeletal problem most commonly encountered in the clinic and adversely affecting quality of life. Kinesophobia can negatively affect the treatment of low back pain and may increase the rate of disability. The purpose of this study was to compare of pain, kinesiophobia and quality of life in patients with low back pain.

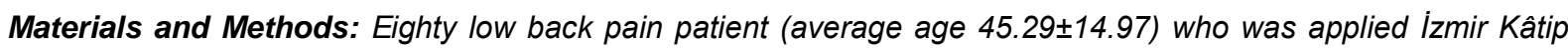
Çelebi University Atatürk Training and Research Hospital, Clinic of Physical Therapy and Rehabilitation were included. Kinesiophobia by the Tampa Scale for Kinesiophobia, pain severity was evaluated by using Visual Analogue Scale, and quality of life by SF-36 quality of life index.

\footnotetext{
Yazışma Adresi: Sevtap Günay Uçurum

İzmir Katip Çelebi Üniversitesi Sağlık Bilimleri Fakültesi,

Fizyoterapi ve Rehabilitasyon Kliniği, İzmir, Türkiye

Makalenin Geliş Tarihi: 31.03.2017 Kabul Tarihi: 20.06.2017
} 
Results: Rest pain was $3.10 \pm 2.75$ and activity pain $6.66 \pm 2.38$. Average Kinesiophobia score was $43.15 \pm 6.16$ and average SF-36 Physical and mental components score was 56.25 $24.42 a n d 62.95 \pm 20.56$, respectively. Kinesiophobia score showed a significant correlation with age $(r=0.285 / \mathrm{p}=0.011)$, rest and activity pain $(r=0.242 / p=0.032$ and $r=0.293 / p=0.008)$, educational level $(r=-0.279 / p=0.002)$, SF-36 physical component $(r=-$ $0.236 / p=0.035)$ and mental score $(r=-0.323 / p=0.003)$.

Conclusion: While kinesophobia correlated positively with age, rest and activity pain in patients with low back pain, it showed negative correlation with education status, physical and mental components of quality of life.

Keywords: Low back pain, kinesiophobia, quality of life.

\section{Giriş}

Bel ağrısı yaşam kalitesini olumsuz etkileyen, verimliliği azaltan ve günlük yaşam aktivitelerini yapılabilme becerisini sınırlayan klinikte yaygın olarak karşılaştığımız bir kas iskelet sorunudur $(1,2)$. Yaşam boyu genel nüfusun \%65-80 'inde oluşabilen ve görülme oranı giderek artan bir sağlık sorunudur (3). Kişinin motivasyonunu etkileyerek, fiziksel ve psikolojik problemlere de yol açabilir (1).

Biyopsikososyal modele göre insan postüründeki değişimler, kas kuvvet dengesizlikleri, eklemlerde oluşan problemler, hareket kısıtılıkları gibi omurgaya ait problemler ve alt ekstremite problemlerinin yanı sıra, düşünceler, tutumlar ve davranışlar da kronik bel ağrısını etkileyebilir $(4,5)$. Stres, anksiyete ve depresyon ağrıya sekonder gelişebilir, anksiyete ve depresyon ağrı duyarlılığını arttırabilir (2,6). Ağrıyı genel olarak 3 aydan az süren potansiyel doku hasarı ile birlikte bir uyarana karşı oluşan, hoş olmayan emosyonel bir cevap olarak tanımlayabiliriz. Doku hasarı düzeldikten sonra bile ağrının hissedilmesi, ağrının artık doku hasarına bağlı bir belirti olmadığı ve ağrı davranışının primer hastalık haline geldiği ve kendine özgü özelliklerinin olduğu, normal olmayan bir durumdur (7).

Kinezyofobi yeniden yaralanma ya da hareketle ağrı oluşması korkusu olarak tanımlanabilir $(8,9)$. Kronik vakalarda ağrı şiddeti ve ağrıya kognitif yanıt fonksiyonel bozukluklar ile beraber oluşur. Ağrılı durumda verilen kognitif yanıtlar korku kaçınma modelini oluşturur $(1,10)$. Kinezyofobi hastalarda hareketin yeniden yaralanmaya veya ilave ağrıya yol açacağı inancı oluştuğu için, ağrının kalıcı olmasında bir risk faktörüdür. Bel ağrılı hastalarda erken dönem mobilizasyon ve egzersizin yararlı olduğu, hareketsizliğe bağlı olarak ağrının arttığı ve bunun sonucunda uyku problemleri ve depresyonda artmanın görüldüğü yapılan araştırmalarda tespit edilmiştir (11). Ağrı sonucunda oluşan kinezyofobi aktivitelerde kısıtlanmaya neden olmakta, bunun sonucunda fiziksel kapasitede, kuvvet ve esneklikte azalma görülmektedir. Hareketten kaçınma korkusu sonucunda bel ağrısının düzgün tedavi edilememesi, buna bağlı iş günü kayıpların artması, yaşam kalitesinde azalma, depresyona yatkınlık, uyku düzeninde azalma da karşımıza çıkacak problemler arasındadır $(2,3,12-14)$.

Kronik bel ağrısı ve fonksiyonel yetersizlik gelişiminde ağrıya bağlı korku ve kaçınma davranışlarının rolünün anlaşılması, bel probleminin tedavisinde ve özür oranının azaltılmasında önemli katkı sağlayabilir.

Çalışmamızda bel ağrısı olan kişilerde kinezyofobi oluşup, oluşmadığını görmeyi ve oluşan kinezyofobi ile ağrı ve yaşam kalitesi arasındaki ilişkiyi değerlendirmeyi amaçladık.

Çalışmamızın etik kurul onayı İzmir Katip Çelebi Üniversitesi Girişimsel Olmayan Klinik Araştırmalar Etik Kurulu'ndan alındı (Karar No: 33/ 22.02.2017).

\section{Gereç ve Yöntem}

Çalışmamız bel ağrısı problemi olan hastalarda kinezyofobi varlığını belirlemek ve kinezyofobi varsa bunun ağrı, özür ve yaşam kalitesi üzerine etkisini araştırmak amacıyla bir anket çalışması olarak planlandı. Çalışmaya İzmir Kâtip Çelebi Üniversitesi Atatürk Eğitim ve Araştırma Hastanesi Fizik Tedavi ve Rehabilitasyon Kliniği'ne başvuran bel ağrısı şikayeti olan, en az 6 haftadır şikayetleri devam eden, 18-80 yaş aralığında gönüllü 80 kişi dâhil edildi. Herhangi bir omurga ve pelvise ait kırık ya da cerrahi geçirmiş olan, inflamatuvar bir hastalığı olan ya da nörolojik, duyusal ve kassal paralizisi bulunan hastalar çalışma dışında bırakıldı. Çalışmaya katılan kişilerin cinsiyet, yaş, boy, kilo, şikayet süresi, eğitim durumu gibi kişisel bilgileri oluşturulan değerlendirme formu ile, hissettikleri ağrı miktarı "Görsel Anolog Skalası (GAS) ile, kinezyofobi varlığı "Tampa Kinezyofobi Ölçeği (TÖK)" ile ve yaşam kaliteleri SF-36 Yasam kalitesi anketi" ile değerlendirildi.

GAS ağrının algılanma şiddetini belirlemeye yarayan kas iskelet sistemi ile ilgili çalışmalarda 
sıklıkla kullanılan geçerliliği ve güvenilirliği kanıtlanmış bir skaladır. $100 \mathrm{~mm}$ uzunluğunda yatay bir çizgiden oluşmaktadır. Çizginin başında ve sonunda iki işaret bulunmaktadır. Çizginin başındaki işaret $0 \mathrm{~mm}$-hiç ağrı olmadığı durumu, çizginin sonundaki işaret $100 \mathrm{~mm}$-dayanılmaz ağrıyı ifade eder (15). Kişilerden istirahat ve aktivite sırasında hissettikleri maksimum ağrı için bu horizontal çizgi üzerine bir işaret koymaları istendi ve sonuçlar $\mathrm{cm}$ cinsinden kaydedildi.

TÖK muskuloskeletal ağrı için geliştirilmiş, Türkçe geçerlilik ve güvenilirliği yapılmış olan 17 soruluk bir ankettir $(16,17)$. Ölçekte her soru için 4 puanlık Likert puanlama sistemi (1=Kesinlikle katılmıyorum, 2=Katılıyorum, 3=Katılmıyorum, 4=Tamamen katılıyorum) kullanılmaktadır. Anket sonucunda kişi verdiği cevaplara göre 17-68 arasında total bir skor almaktadır. Ölçekte kişinin aldığı puanın yüksek oluşu kinezyofobisinin de yüksek olduğunu göstermektedir (16). Çalışmamızda kişilerin verdikleri yanıtlar doğrultusunda toplam puan kaydedildi.

SF-36 birçok amaç için kullanılabilen, 36 sorudan oluşan, kişinin sağlık durumunu belirleyen ve Türkçe geçerlilik ve güvenilirlik çalışması yapılmış olan bir ankettir $(18,19)$. Bu ankette fiziksel fonksiyonellik, ağrı, fiziksel sağlık, canlılık, mental sağlık, sosyal fonksiyonellik ve duygusal rol olarak 8 bileşen mevcuttur ve Likert puanlama sistemi kullanılır (20). Puanlama 100 puan üzerinden yapılmaktadır ve alınan puanlar her bileşen için 0 ile 100 puan arasındadır (18). Çalışmamızda kişilerin verdikleri yanıtlar doğrultusunda ölçeğin fiziksel sağlık ve mental sağlık bileşenleri kaydedildi.

Çalışma için gerekli örneklem büyüklüğünü belirleyebilmek amacı ile $G^{*}$ Power ( $G^{*}$ Power Ver. 3.0.10, Franz Faul, Universität Kiel, Germany) paket programı kullanıldı. Çalışmada, $\alpha=0.05$ tip I hata, $r=0.3$ etki büyüklüğü ile $\% 80$ güç elde edebilmek için en az 64 olgudan oluşan bir örneklem alınmasına gerek olduğu hesaplandı. Bu çalışmada 80 kişiye ulaşıldı. Bu örneklem büyüklüğü ile çalışmanın gücü $\alpha=0.05$ tip $\mid$ hata, $r=0.3$ etki büyüklüğü ile \%85 olarak hesaplandı.

Elde edilen tüm verilerin analizi SPSS 16.0 for Windows istatistik programı kullanılarak yapılmıştır. Verilerin normal dağılım gösterip göstermedikleri Shapiro Wilks testi ile incelenmiştir. Test sonucunda verilerin normal dağılmadığı görülmüştür. Kinezyofobi değerleri ile yaşam kalitesi ve ağrı parametreleri arasındaki ilişki verilerimiz nonparametrik olduğu için Spearman korelasyon analizi Cilt 57 Sayı 3, Eylül 2018 / Volume 57 Issue 3, September 2018 ile değerlendirilmiştir. Eğitim durumu ve kinezyofobi arasındaki ilişki Kendall'ın tau-b katsayısı korelasyon analizi ile değerlendirildi. İstatistiksel anlamlılık düzeyi $p<0.05$ 'dir.

\section{Bulgular}

Çalışmaya katılan bireylerin sosyo-demografik özellikleri, kinezyofobi ve yaşam kalitesi değerleri Tablo-1'de gösterilmiştir.

Tablo-1. Bireylerin Demografik Bilgileri, Yaşam Kalitesi ve Kinezyofobi Ölçümleri.

\begin{tabular}{|c|c|}
\hline Değişkenler & Ortalama $\pm S S$ \\
\hline Yaş(yıl) & $45.29 \pm 14.97$ \\
\hline Beden kitle indeksi $\left(\mathrm{kg} / \mathrm{m}^{2}\right)$ & $26.86 \pm 5.67$ \\
\hline $\begin{array}{c}\text { Cinsiyet (\%) } \\
\text { Kadın } \\
\text { Erkek }\end{array}$ & $\begin{array}{l}60(\% 75) \\
20(\% 25)\end{array}$ \\
\hline Şikâyet süresi (ay) & $18.6 \pm 17.72$ \\
\hline $\begin{array}{l}\text { Eğitim durumu (\%) } \\
\text { Okur yazar değil } \\
\text { Illkokul } \\
\text { Ortaokul } \\
\text { Lise } \\
\text { Üniversite }\end{array}$ & $\begin{array}{c}2(\% 2.5) \\
37(\% 46.3) \\
4(\% 5) \\
17(\% 21.3) \\
20(\% 25)\end{array}$ \\
\hline İstirahat GAS & $3.10 \pm 2.75$ \\
\hline Aktivite GAS & $6.66 \pm 2.38$ \\
\hline SF-36 fiziksel komponent & $56.25 \pm 24.42$ \\
\hline SF-36 mental komponent & $62.95 \pm 20.56$ \\
\hline TKÖ & $43.15 \pm 6.16$ \\
\hline
\end{tabular}

Çalışmamıza 60'ı kadın 20'si erkek olmak üzere toplam 80 olgu dâhil edildi. Yaş ortalamaları 45.29 \$14.97 yıl ve ortalama şikâyet süreleri $18.6 \pm 17.72$ ay olan bireylerin, istirahat sırasındaki GAS değeri ortalaması $3.10 \pm 2.75$, aktivite sırasındaki GAS değeri ortalaması $6.66 \pm 2.38$ olup

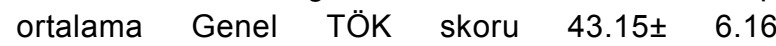
bulunmuştur. Ortalama SF-36 fiziksel sağlık skoru $56.25 \pm 24.42$ ve ortalama SF-36 mental sağlık skoru $62.95 \pm 20.56$ puandır. Bireylerin kinezyofobi değerleri ile yaşları $(r=0.237 / p=0.034)$, istirahat ve aktivite sırasındaki GAS değerleri $(r=0.269 / p=0.016$ ve $r=0.321 / p=0.004)$, eğitim durumları ( $r=-$ $0.312 / p=0.005)$, yaşam kalitesinin fiziksel ( $r=-$ $0.220 / p=0.048$ ) sağlık ve mental sağlık ( $r=$ $0.286 / p=0.010$ ) parametreleri arasında anlamlı bir ilişki bulunmuştur. Bireylerin kinezyofobi değerleri ile yaşları, istirahat ve aktivite sırasındaki GAS değerleri arasında pozitif yönde zayıf bir korelasyon bulunurken; eğitim durumları, yaşam kalitesinin fiziksel ve mental komponenet parametreleri arasında negatif yönde zayıf bir korelasyon bulunmuştur. $(p<0.05)($ Tablo-2). 
Tablo 2. Bireylerin Kinezyofobi Düzeyi İle Diğer Parametreler Arasındaki İlişki.

\begin{tabular}{lll}
\hline & $\mathbf{r}$ & $\mathbf{p}$ \\
\hline Yaş & $.285^{\star}$ & $.011^{\star}$ \\
Şikâyet süresi & $.007^{\star}$ & .950 \\
Eğitim durumu & $-.279^{+}$ & $.002^{\star \star}$ \\
İstirahat GAS & $.242^{\star}$ & $.032^{\star}$ \\
Aktivite GAS & $.293^{\star}$ & $.008^{\star \star}$ \\
SF-36 fiziksel komponent & $-.236^{\star}$ & $.035^{\star}$ \\
SF-36 mental komponent & $-.323^{\star}$ & $.003^{\star \star}$ \\
\hline
\end{tabular}

$\mathrm{r}=+$ Kendalf ın tau-b Katsayısı, * Spearman korelasyon katsayısı, GAS: Görsel analog skalası.

$\mathrm{p}={ }^{*}$ anlamlılık düzeyi $0.05,{ }^{* *}$ anlamlılık düzeyi 0.01

\section{Tartışma}

Çalışmamızda bel ağrısı olan olgularda oluşan kinezyofobinin değerlendirilmesi ve bunun ağrı ve yaşam kalitesi ile olan ilişkisinin belirlenmesini amaçladık. Bel ağrısı olan olgularımızda yüksek oranda kinezyofobi geliştiğini ve bunun da yaş, eğitim durumu, ağıı ve yaşam kalitesiyle ilişkili olduğunu bulduk. Bireylerin kinezyofobi değerleri ile yaş, istirahat ve aktivite sırasındaki GAS değerleri arasında pozitif yönde zayıf bir korelasyon bulunurken, eğitim durumları, yaşam kalitesinin fiziksel ve mental komponent parametreleri arasında negatif yönde zayif bir korelasyon bulundu.

Kinezyofobi ağrılı bir yaralanma ya da yeniden yaralanma durumuna hassasiyet hissiyle sonuçlanan, fiziksel hareket ve aktivitenin zayıflatıcı, mantık dışı ve aşırı korkusu olarak ifade edilmektedir (21). Ağrı şiddeti ve ağrıya kognitif cevaplar fonksiyonel bozuklukla ilişkilidir(1). Bu durum bireylerin normal fonksiyonunu yeniden kazanmasını önler, özürlülüğü arttııı ve rehabilitasyonu olumsuz yönde etkiler $(4,22)$.

Meewisse ve ark. (16) yaptıkları çalışmalarında akut bel ağrılı hastalarda hem kinezyofobi hem de korku-kaçınma davranışlarının ağrıyla ilişkili olduğunu bildirmişlerdir. Picavet ve ark. (8) 1845 kronik bel ağrilı hastayla yürütmüş oldukları çalışmada ağrı ve kinezyofobi arasındaki ilişkiyi ortaya koymuşlardır. Buna karşılık Thomas ve ark. (24) tarafından yapılan 50 kronik bel ağrılı hastasının dahil edildiği çalışmada ağrı ile kinezyofobi arasında bir ilişki olmadığını göstermişlerdir. Uluğ ve ark. (1), 300 bel ağrılı ve 300 boyun ağrılı hastayla yürütmüş oldukları çalışmada ağrının her iki grupta benzer olduğu ancak fiziksel aktivite skorları ve kinezyofobi ölçeği değerlerinin bel ağrılı grupta önemli derecede daha yüksek olduğunu bildirmişlerdir. Biz de çalışmamızda benzer şeklide bel ağrısı olan kişilerde önemli derecede kinezyofobi olduğunu, hem istirahat GAS değerleri hem de aktivite GAS değerleri ile kinezyofobi değerleri arasında ilişki olduğunu bulduk. Bununda ağrının varlığında hastaların yapacakları egzersizin ya da 134 hareketin onların ağrılarını daha fazla arttıracağı düşüncesine sahip olmalarılla ilişkilendirdik.

Mason ve ark. (12) tarafından yapılan 86 kronik bel ağrılı hastanın dahil edildiği çalışmada ortaya çıkan ağrı ve bu ağrı şiddetinin yaşam kalitesi üzerinde önemli rol oynadığı gösterilmiştir. Bergsten ve ark. (22) 265 hastayla yapmış oldukları çalışmada, yüksek TAMPA kinezyofobi ölçeği skoruna sahip hastaların yarısında yüksek özür oranı bulmuş, kinezyofobi ve özürlülük arasında düşük korelasyon olduğunu ifade etmişlerdir. Antunes ve ark. (2) tarafından yapılan çalışmaya 193 kronik bel ağrılı birey katılmış olup bireyler depresyonu olan ve olmayanlar şeklinde iki gruba ayrımıştır. Depresyonu olan grupta ağrı, kinezyofobi ve yaşam kalitesiyle ilişkili parametre skorlarının daha kötü olduğu gösterilmiştir. Mayalı ve ark. (3) tarafından yapılan çalışmada kronik bel ağrıl hastaların özürlülük düzeyinin daha yüksek, SF-36 yaşam kalitesi ölçeğinde ağrı ve fiziksel fonksiyonu ifade eden paremetre skorlarının daha düşük olduğu gösterilmiştir. Monticone ve ark. (5) kronik bel ağrılı 90 hastanın katıldığı randomize kontrollü çalışmasında kinezyofobinin gelişimi ve kalıcılığında psikolojik faktörlerin de rol oynadığı vurgulanmış ve egzersiz programıyla karşılaşııııldığında uzun süreli multidisipliner yaklaşımın özürlülük, korkukaçınma davranışları ve ağrıyı azaltı̆ı̆ı, yaşam kalitesini iyileştirdiği ifade edilmiştir. Yine benzer şekilde Trocoli ve ark. (23) tarafından çalışmada kinezyofobi ile anksiyete ve depresyon arasında pozitif korelasyon olduğu bildirilmiştir. Altuğ ve ark. (25), 112 kronik bel ağrılı hastanın katılığı çalışmada kinezyofobi ve yaşam kalitesi parametreleri arasındaki ilişkiyi araştırmışlardır ve kinezyofobi varığının, yaşam kalitesinin tüm parametreleri ile negatif bir ilişki içinde olduğunu tespit etmişlerdir. Aynı şekilde Uluğ ve ark. (1) yapmış oldukları çalışmalarında bel ağrılı olgularda yüksek şiddette kinezyofobi geliştiğini ve bu kinezyofobinin yaşam kalitesini olumsuz etkilediğini bulmuşlardır. Biz de çalışmamızda literatürle benzer olarak kinezyofobi ile yaşam kalitesinin fiziksel ve mental sağlık parametreleri arasında negatif yönde zayıf bir ilişki bulduk. Kinezyofobi yaş ve ağrı ile beraber artarken, aynı zamanda kişinin yaşam kalitesinin azaldığını tespit ettik.

Çalışmamızla ilgili bazı kısıtılıklarımız mevcuttur. Bunlardan ilki kişi sayısıdır. Çalışmamıza 80 hastayı dâhil ettik, ancak örneklem sayısının arttırıması hata payını en aza indirmek için daha uygun olurdu. Íkincisi çalışmaya dâhil edilen kişiler bel problemlerine göre kategorize edilebilirdi. Üçüncüsü şikâyet süreleri akut, subakut ve kronik olarak sınıflandırılabilirdi. Böyle bir sınıflandırma her evredeki ağrı, kinezyofobi ve yaşam kalitesini ayrı olarak hesaplamaya olanak tanır ve hem hasta şikâyet profili hem de uygulanacak tedavi yönetimi açısından fizyoterapistlere yol gösterici olurdu. Son olarak sağlıklı

Ege Tıp Dergisi 
kişilerden oluşan bir kontrol grubu çalışmaya dâhil edilebilir ve her iki grup arasında karşılaştırma yapılabilir, incelenen parametrelerin sağlıklı ve hasta bireyler arasındaki farkları hesaplanabilirdi.

\section{Sonuç}

Bel ağrılı hastalarda yüksek derecede kinezyofobi ortaya çıkmakta, yaşam kalitesinin fiziksel ve mental sağlık komponentleri olumsuz etkilenmektedir. Buna ek olarak kinezyofobi nedeniyle hastalar aktivitelerini kısıtlar ve egzersiz yapmaktan kaçınabilirler. Bu durum hastaların düzgün bir şekilde tedavi edilebilmelerini engelleyebilir ve ağrının kronikleşmesine, özür oranının artmasına neden olabilir. Bu nedenle bel ağrılı hastaların tedavisinde fizyoterapi uygulamalarının yanı sıra kinezyofobinin de çözülmesini sağlayacak multidisipliner yaklaşımların tercih edilmesi daha uygun olabilir.

\section{Kaynaklar}

1. Uluğ N, Yakut Y, Alemdaroğlu I, et.al. Comparison of pain, kinesiophobia and quality of life in patients with low back and neck pain. J Phys Ther Sci 2016;28(2):665-70.

2. Antunes RS, Macedo BGD, Amaral TDS, et al. Pain, kinesiophobia and quality of life in chronic low back pain and depression. Acta Ortop Bras 2013;21(1):27-9.

3. Mayalı FT, Oz B, Gulpek D, et al. The effect of depressive emotional state on the Efficacy of Physical Therapy in Patients with Low Back Pain. MBSJHS 2016; 2(2), 6-13.

4. Monticone M, Ambrosini E, Rocca B, et al. A multidisciplinary rehabilitation programme improves disability, kinesiophobia and walking ability in subjects with chronic low back pain: Results of a randomised controlled pilot study. Eur Spine $J$ 2014;23(10):2105-13.

5. Monticone M, Ferrante S, Rocca B, et al. Effect of a long-lasting multidisciplinary program on disability and fear-avoidance behaviors in patients with chronic low back pain: Results of a randomized controlled trial. Clin J Pain 2013;29(11):929-38.

6. Andersson GB. Epidemiological features of chronic low-back pain. The lancet 1999;354(9178);581-5.

7. Roditi D, Robinson ME. The role of psychological interventions in the management of patients with chronic pain. Psychol Res Behav Manag 2011;4(1):41-9.

8. Picavet HSJ, Vlaeyen JW, Schouten JS. Pain catastrophizing and kinesiophobia: Predictors of chronic low back pain. Am J Epidemiol 2002;156(11):1028-34.

9. Neblett R, Hartzell MM, Mayer TG, et.al. Establishing clinically meaningful severity levels for the Tampa Scale for Kinesiophobia (TSK-13). Eur J Pain 2016;20(5):701-10.

10. Vincent HK, Omli MR, Day T, et al. Fear of movement, quality of life, and self-reported disability in obese patients with chronic lumbar pain. Pain Med 2011;12(1):154-64.

11. Veehof MM, Oskam MJ, Schreurs KM, et al. Acceptance-based interventions for the treatment of chronic pain: A systematic review and meta-analysis. Pain 2011;152(3):533-42.

12. Mason VL, Mathias B, Skevington SM. Accepting low back pain: Is it related to a good quality of life? Clin J Pain 2008;24(1):22-9.

13. Henrotin YE, Cedraschi C, Duplan B, et al. Information and low back pain management: A systematic review. Spine 2006;31(11):326-34.

14. Chung S, Lee J, Yoon J. Effects of stabilization exercise using a ball on mutifidus cross-sectional area in patients with chronic low back pain. J Sports Sci Med 2013;12(3):533-41.

15. Ohnhaus EE, Adler R. Methodological problems in the measurement of pain: A comparison between the verbal rating scale and the visual analogue scale. Pain 1975;1(4);379-84.

16. Swinkels-Meewisse EJCM, Swinkels RAHM, Verbeek ALM, et al. Psychometric properties of the Tampa Scale for kinesiophobia and the fear-avoidance beliefs questionnaire in acute low back pain. Manual Ther 2003;8(1):29-36.

17. Yilmaz ÖT, Yakut Y, Uygur F, et al. Tampa kinezyofobi ölçeğinin Türkçe versiyonu ve test-tekrar test güvenirliği. Fizyoterapi Rehabilitasyon $2011 ; 22(1): 44-9$.

18. Ware JE. SF-36 health survey update. Spine 2000;25(24):3130-9.

19. Kocyigit $\mathrm{H}$, Aydemir $\mathrm{O}$, Olmez N, et al. Reliability and validity of the Turkish version of short-form-36 (SF-36). Turkish $\mathrm{J}$ Drugs Therap 1999;12(2):102-6.

20. McHorney CA, Ware Jr JE, Lu JR, et al. The MOS 36-item short-form health survey (SF-36): III. Tests of data quality, scaling assumptions, and reliability across diverse patient groups. Medical Care 1994;32(1):40-66.

21. Kori SH, Miller RP, Todd DD. Kinesiophobia: A new view of chronic pain behavior. Pain Manag 1990;3(1):35-43.

22. Lüning Bergsten $C$, Lundberg $M$, Lindberg $P$, et al. Change in kinesiophobia and its relation to activity limitation after multidisciplinary rehabilitation in patients with chronic back pain. Disabil Rehabil 2012;34(10):852-8.

23. Trocoli TO, Botelho RV. Prevalence of anxiety, depression and kinesiophobia in patients with low back pain and their association with the symptoms of low back spinal pain. Rev Bras Reumatol 2016;56(4):330-6.

24. Thomas EN, Pers YM, Mercier G, et al. The importance of fear, beliefs, catastrophizing and kinesiophobia in chronic low back pain rehabilitation. Ann Phys Rehabil Med 2010;53(1):3-14.

25. Altuğ F, Ünal A, Kilavuz G, Kavlak E, Çitişli V, Cavlak U. Investigation of the relationship between kinesiophobia, physical activity level and quality of life in patients with chronic low back pain. J Back Musculoskelet Rehabil 2016;29(3):527-31. 